\title{
Clinical prediction rules in obstructive sleep apnoea syndrome
}

\section{To the Editor:}

I have read with interest the paper in which DeEGAN and McNicholas [1] try to find prediction rules for obstructive sleep apnoea syndrome (OSAS). Yet, there are several questions I would like to pose:

1) The need for clear-cut guidelines for assessment of OSAS patients has been recently stressed [2, 3]. In this sense, my question is: why is an apnoea-hypopnoea index (AHI) of 15 events $\cdot \mathrm{hr}^{-1}$ used to define OSAS, instead of the "classical" 5-10 events.hr-1 [4-6] or the "new" 5 events $\cdot \mathrm{hr}^{-1}[2,7]$ ? It is well known that modifications in the threshold of positivity produce changes in the prevalence of a certain disease and in the performance of diagnostic tests (as can be seen in table 6 [1]). Moreover, I wonder if considering a threshold of 5 or 10 events $\cdot$ hr $^{-1}$, could have had another consequence: modifying the parameters included in the prediction rules, and their relative weight, so that other prediction equations could have been obtained. I would be pleased if the authors could answer this question.

2) There is another index derived from oximetric recordings that can be of practical interest, the percentage of time during which arterial oxygen saturation $\left(\mathrm{Sa}_{2} \mathrm{O}_{2}\right)$ is $<90 \%$ (CT90). Perhaps the addition of CT90 to the prediction model could add accuracy.

3) The authors do not state how many of their patients had chronic obstructive pulmonary disease (COPD). Since it has been shown that oximetry is an inaccurate screening procedure for OSAS in COPD [5, 8], one may wonder if the diagnostic performance of the oximetric predictive model is higher for non-COPD patients than for COPD patients. Have the authors analysed this potential difference in behaviour?

4) The multiple linear regression model proposed by the authors yields a determination coefficient of 0.189 , or a correlation coefficient (r) of 0.435 , which differs significantly from 0 . Is this enough? A determination coefficient of 0.189 means that only $18.9 \%$ of the total variation in AHI is explained by the three explicative variables (alcohol consumption, BMI and age), and that $81.1 \%$ of the total variation remains unexplained. Considering these data and the conditions for applying a regression equation (all the variables involved follow a Gaussian distribution, that $\mathrm{r}$ differs from 0 , and that $\mathrm{r}$ is high enough, i.e. at least 0.5 , and preferably at least 0.6 [9]), I cannot accept that AHI can be estimated from these clinical features, and my conclusion would be that further studies are needed.

5) The authors propose that a clinical probability score (CPS) of $<0.26$ can be considered to exclude OSAS, and a CPS $\geq 0.54$ is very helpful in confirming OSAS. In the same way, an oximetric probability score (OPS) of $<0.2$ excludes OSAS, and OPS $\geq 0.86$ confirms OSAS. So, from these data, it can reasonably be concluded that CPS $<0.26+$ OPS $<0.20=$ non-OSAS, and that CPS $\geq 0.54+$ OPS $\geq 0.86=$ OSAS. However, what is the sit- uation for intermediate values of both scores, or those instances in which one of these scores clearly supports or rejects the diagnosis of OSAS and the other yields an intermediate values? It seems sensible to suggest that intermediate values can correspond to hypopnoeic patients (with no apnoeas), upper airways resistance syndrome, or mild OSAS. Nevertheless, there may be instances of apparently doubtful cases that are not included in any of these diagnoses. For instance, can a 31-year-old female, who does not snore every night, has observed apnoeas, does not doze while driving, does not drink and is not obese (CPS $=0.361$ ) but who has 129 desaturations $\geq 4 \%$ (desaturation index of $19 \mathrm{hr}^{-1}$ ) and a minimum $\mathrm{Sa}_{\mathrm{a}} \mathrm{O}_{2}$ of $74 \%$ (OPS $=0.976$ ) be considered as having an a priori nonpredictable overall prepolysomnography study? There can be no doubt that this patient has OSAS. Furthermore, how should we consider a $40 \mathrm{yr}$ old, everyday-snoring, driving-dozing, apnoeic, nondrinking, nonobese male $(\mathrm{CPS}=0.551)$ who has 40 desaturations and whose lower $\mathrm{Sa}_{\mathrm{a}} \mathrm{O}_{2}$ is $88 \%(\mathrm{OPS}=0.468)$ ? Could a joint score (weighted or non-weighted) be useful in these "borderline" situations? Or, should the clinical or the oximetric score be more important in case of disagreement or indetermination?

I agree that more studies are needed to assess clinically valid prediction rules, but first we must reach a consensus on basic issues concerning diagnosis and management $[2,3]$.

\section{References}

1. Deegan PC, McNicholas WT. Predictive value of clinical features for the obstructive sleep apnoea syndrome. Eur Respir J 1996; 9: 117-124.

2. Strohl KP, Redline S. Recognition of obstructive sleep apnea. Am J Respir Crit Care Med 1996; 154: 279-289.

3. McNicholas WT. Diagnostic criteria for the sleep apnoea syndrome: time for consensus? Eur Respir J 1996; 9: 634-635.

4. Bresnitz EA, Goldberg R, Kosinski RM. Epidemiology of obstructive sleep apnea. Epidemiol Rev 1994; 16: 210-227.

5. Barbé F, Amilibia J, Capote F, et al. Grupo de trabajo del Area de Insuficiencia Respiratoria y Trastornos del Sueño. Diagnóstico del síndrome de apneas obstructivas durante el sueno. Informe de consenso del Area de Insuficiencia Respiratoria y Trastornos del Sueño. Arch Bronconeumol 1995; 31: 460-462.

6. Martín Trigo JM, Arán Corbella X, Barbé Illá F, et al. Grupo de trabajo SEPAR. Normativa sobre diagnóstico y tratamiento del síndrome de apnea obstructiva del sueño (SAOS). Barcelona, Ediciones Doyma, S.A.J 1993.

7. Chervin RD, Guilleminault C. Obstructive sleep apnea and related disorders. Neurol Clin North Am. 1996; 14: 583-609.

8. Cordovilla R, Jiménez A, Cifrián JM, Golpe R, García Pérez M, Carpizo R. Papel de la pulsioximetria nocturna en el diagnóstico del síndrome de apneas del sueño (SAS). Salamanca, Procceedings of the 14th Congress of the Castilian-Leonese Respiratory Society (SOCALPAR) 1995: 121-122. 
9. Carrasco de la Peña JL. El método estadístico en la investigación médica. Madrid, Editorial Karpos, S.A., 1982: 190-192.

\section{A. Díez Herranz}

Unidad de Neumología, Gabinete Médico "Paracelso", Valladolid, Spain.

\section{$\underline{R E P L Y}$}

\section{From the authors:}

We thank Dr Herranz for his interest in our paper, and welcome the opportunity to respond.

1) He questions our choice of an apnoea/hypopnoea index (AHI) of 15 events $\cdot \mathrm{hr}^{-1}$ to define obstructive sleep apnoea (OSA). As mentioned in the discussion section of our paper, we chose this level as patients with an AHI $>15$ events $\cdot \mathrm{hr}^{-1}$ are likely to have clinically significant OSA, and would usually be considered for nasal continuous positive airway pressure (CPAP) therapy. Furthermore, this is a level which has been widely used in other papers quoted in our manuscript [1, 2, 3], although we recognise that many centres use an AHI threshold of 10 events.hr-1. The "classical" threshold of 5 events $\cdot \mathrm{hr}^{-1}$ has traditionally referred to apnoea rather than apnoea and hypopnoea frequency, and an AHI level of 5 events $\cdot \mathrm{hr}^{-1}$ to define clinically significant OSA is not widely used.

In the paper, we discussed in detail the impact on our conclusions of reducing the AHI threshold to 10 and raising it to 20 events $\cdot \mathrm{hr}^{-1}$, including how these thresholds modify the parameters in the prediction rules; table 6 of the manuscript demonstrates separate prediction equations for each level. In general, the lower AHI threshold resulted in increased numbers of patients diagnosed with OSA, without changing the number of patients requiring CPAP. However, we do not advocate a rigid AHI threshold to define OSA in clinical practice, as some patients with an AHI level $<15$ events $\cdot \mathrm{hr}^{-1}$ may have significant symptoms such as daytime somnolence, and may warrant a trial of nasal CPAP. Ultimately, it is up to the clinician to weigh clinical and laboratory data, and make an appropriate management decision based on the complete information.

2) We recognise that the CT90 may provide additional useful information about nocturnal $\mathrm{Sa}_{\mathrm{a}} \mathrm{O}_{2}$, but see no particular reason why this should improve the predictive accuracy for OSA. The $\mathrm{Sa}_{2} \mathrm{O}_{2}$ pattern of OSA is one of repetitive drops in $\mathrm{Sa}, \mathrm{O}_{2}$ during apnoeas/hypopnoeas with resaturation to normal levels in between, among patients without associated lung disease, and we believe that the frequency and magnitude of these desaturations provide the most useful information. The CT90 index would not help distinguish OSA from other conditions associated with nocturnal hypoxaemia such as COPD and central hypoventilation.

3) Few of our patients had significant COPD, and table 1 demonstrates that the group as a whole had normal pulmonary function. Checking the individual data, approximately $12 \%$ of patients with an AHI less than 15 events $\cdot \mathrm{hr}^{-1}$ and only $7 \%$ of patients with an AHI $>15$ events $\cdot \mathrm{hr}^{-1}$ had an forced expiratory volume in one second $\left(\mathrm{FEV}_{1}\right)<70 \%$ predicted. These numbers are too small to allow a meaningful comparison.

4) Dr Herranz correctly states that the AHI cannot be estimated from clinical variables using a multiple linear regression model, but this was never our intention.
Instead, we sought to determine the probability of a patient having an AHI $>15$ events.hr- ${ }^{-1}$ using logistic regression. The multiple linear regression model was used to study the relative contribution of each feature, while controlling for the other clinical features. The finding of a determination coefficient of 0.189 is to be expected, since it is widely recognised that OSA is a multifactorial condition, with many patients having no readily identifiable upper airway abnormality. Certainly, more of the variation could be explained if we had obtained the opinions of a specialist otorhinolaryngologist in each patient, together with sophisticated upper airway imaging. However, as mentioned in the discussion, we used only those variables that could easily be assessed by a respiratory physician at a single routine outpatient visit. In another study [4], a similar multiple regression equation based on clinical variables yielded an $\mathrm{r}^{2}$ of only $13.6 \%$, even lower than in our paper.

5) Dr Herranz compares the relative contributions of clinical and oximetry scores. This issue has already been addressed in our paper. We recommended, based on our findings, that patients with a CPS score of $>0.54$ should have a limited sleep study as the initial investigation, as many of these patients will have readily recognisable OSA, based on typical oximetry tracings, and full sleep studies will be unnecessary. We did not propose, as Dr Herranz suggests, that a CPS $>0.54$ is very helpful in "confirming" OSA, merely that this level selects out those patients in whom limited studies may be the only investigation required. Similarly, our model would not produce a situation of having intermediate values for both clinical and oximetry scores, since those patients with intermediate clinical scores would undergo more complete sleep studies as their initial sleep laboratory investigation.

We should stress that one of the main aims of our study was to seek ways of reducing the number of full sleep studies required to investigate patients with suspected OSA. We do not advocate doing overnight oximetry in all patients as an initial investigation, and believe that using combined clinical and oximetry scores would not reduce, but increase, the overall number of investigations required.

\section{References}

1. Crocker BD, Olson LG, Saunders NA, et al. Estimation of the probability of disturbed breathing during sleep before a sleep study. Am Rev Respir Dis 1990; 142: 14-18.

2. Gould GA, Whyte KF, Rhind GB, et al. The sleep hypopnea syndrome. Am Rev Respir Dis 1988; 137: 895-898.

3. Douglas NJ, Thomas S, Jan MA. Clinical value of polysomnography. Lancet 1992; 339: 347-350

4. Stradling JR, Crosby JH. Predictors and prevalence of obstructive sleep apnoea and snoring in 1,001 middleaged men. Thorax 1991; 46: 85-90.

W.T. McNicholas, P.C. Deegan

St. Vincent's Hospital, Elm Park, Dublin 4, Ireland. 